\title{
Study of Brain Plasticity Ramps up in the 1970s: New Phenomena and New Explanations
}

\author{
Gerald E. Schneider \\ Department of Brain and Cognitive Sciences, Massachusetts Institute of Technology, Cambridge, Mass., USA
}

Schneider GE (1970): Mechanisms of functional recovery following lesions of visual cortex or superior colliculus in neonate and adult hamsters. Brain Behav Evol 3:295-323.

Schneider GE (1973): Early lesions of superior colliculus: factors affecting the formation of abnormal retinal projections. Brain Behav Evol 8:73-109.

In the autumn of 1966, shortly after completion of $\mathrm{PhD}$ thesis work, I began experiments on brain damage inflicted early in life. In the thesis work I had done experimental studies of behavioral effects of brain damage - published in two papers [Schneider, 1967, 1969]. This work led to my experimental quest to find underlying mechanisms that could explain why behavioral effects of early lesions were so different from effects of adult lesions. I knew that there may be neuroanatomical changes after damage when the brain was still developing - changes that did not occur after damage suffered later in life. I felt that if no alterations in pathways occurred, then some basic assumptions we were making about brain-behavior relationships might have to be called into question. My hope was to do postdoctoral work with the well-known neuroanatomist Walle J.H. Nauta, the inventor of silver-staining methods for tracing axonal pathways (at that time, the most sensitive methods for tract tracing). When I discussed this plan with my department head at MIT, HansLucas Teuber, he told me that Nauta would soon be coming to MIT as the first neuroanatomist to join a psychology department faculty. After Professor Nauta had arrived and set up his laboratory, I made his acquaintance and began interacting with people working in his lab. Soon I had ar- ranged with Nauta to join his lab for postdoctoral work after receiving my graduate degree. He was interested in the plan to undertake neuroanatomical studies of animals with early brain damage. We discussed using paradigms that had not long before been used to find evidence of collateral sprouting in the spinal cord and brain of adult cats and rats after selective damage to axonal pathways.

Nauta and I began the project by making lesions of visual cortex in neonatal cats. However, we found it difficult to keep the kittens alive, and I suggested that we try using hamsters for the project. I was already very familiar with Syrian hamsters from my thesis studies of behavioral effects of lesions of the visual system, and hamsters have a special advantage for studies of early brain damage - they are born in a very immature state, on the sixteenth day of gestation. Soon we were making visual cortex lesions in hamster nestlings. Walle Nauta was a very experienced and skillful surgeon, whereas I was still acquiring surgical skills. Nauta operated on the first hamsters in the experiments, removing the visual cortex. When I attempted the same surgery on my own, in some cases the lesion was too deep and there was damage to the underlying superior colliculus. When I traced the retinal projections in the first case in which the midbrain tectum had been damaged in a baby hamster, the results were really amazing. For the first time I observed dramatic changes in the subcortical projections of the retina.

In many of the cases we made unilateral lesions so we could compare projections of both eyes in the same animals and look for asymmetries. I worked out a successful technique for making neonatal lesions of the superior colliculus, this time on purpose, using heat applied through the skull, a skull which was only cartilage in the nestlings. In the midbrain-lesion cases the most dramatic alterations in CNS connections occurred, although lesser changes were also found in cases of early posterior neocortical lesions [Schneider, 1970, 1973].

In the Nauta lab, I focused only on the neuroanatomical aspects of the early lesion studies. The behavioral studies were more time consuming and were not finished until after I had established my own laboratory in the same department at MIT, after an appointment to the faculty in 1967. I wrote a first paper on alterations in retinal projections after early midbrain tectal lesions, submitting it to Science magazine in 1970. Reviewers recognized the novelty of the findings, but one reviewer insisted that the discussion of the findings should be altered: I was told that although it

\section{KARGER}

Fax +4161306 1234 E-Mail karger@karger.ch www.karger.com www.karger.com/bbe
Dr. Gerald E. Schneide

Department of Brain and Cognitive Sciences

Massachusetts Institute of Technology, 46-6021

Cambridge, MA 02139 (USA)

Tel. +1 617253 5795, E-Mail jerry@ mit.edu 
looked like the normal specificity of retinal connections to the midbrain had been altered, it was possible that the phenomenon of embryonic regulation may have occurred after the lesion. I discussed this issue with Professor Nauta, and we agreed that a footnote should be inserted to explain this interpretation. None of the actual findings were in dispute. However, the reviewer was not satisfied with the change, and despite the other very positive reviews and the novelty of the findings, the magazine rejected the paper, to my considerable chagrin.

I did not immediately re-write that rejected first report for submission elsewhere, but focused on extending the work on neonatal brain damage. I had obtained independent grant support and was beginning to give talks on the new findings talks that were well received. One talk stands out in my mind; it was at a symposium at Duke University in 1970 on 'Attention and Brain Function'. At that meeting I met the great British biologist J.Z. Young, who also spoke at the meeting. Young enjoyed interacting with young scientists, and he encouraged me in the approach I was taking, combining experimental neuroanatomy with behavioral studies, and attempting to distinguish different factors involved in the formation of anomalous connections after brain damage during development. These two approaches soon became the topics of the two articles in Brain, Behavior and Evolution [Schneider, 1970, 1973].

As I was conducting behavioral experiments with early-lesion hamsters and controls, I became involved in organizing a meeting at the MIT on 'subcortical visual systems' together with David Ingle. David took the lead in obtaining an agreement with the journal Brain, Behavior and Evolution to publish all the presentations as articles as soon as possible after the meeting. Soon I was busy with reviewing and editing those papers as well as writing my own contribution, an article that has reached the list of the ten most-cited papers in the journal. I was not an experienced writer of scientific papers, despite my surprising success at getting a Science article based on my PhD thesis experiments published in 1969. Looking back at the paper published in 1970 in Brain, Behavior and Evolution, I can see that the paper's figures could have been made simpler for easier understanding by readers; they were filled with details as I tried to sum- marize much of the complex data. Nevertheless, there are many interesting findings in that study that remain relevant today.

I believe that after early cortical lesions anatomical changes not studied in my project may be able to explain how it is that, in studies of humans, early lesions can cause cognitive retardation even when they do not cause sensory or motor problems that would occur after similar damage in adulthood. The animals described in the first of my two Brain, Behavior and Evolution papers were unusually retarded in pretraining, when they had to learn to perform in the testing apparatus. The factors described in the second of my two papers in Brain, Behavior and Evolution (see below) can be used to suggest specific anatomical changes that could account for cognitive retardation after early brain damage. I explained this in a paper published in 1979, written in memory of Hans-Lukas Teuber, relating my own experimental findings to human studies [Schneider, 1979].

I continued the work on early lesions, adding much more information and analysis. I was able to devise a test of a new hypothesis about a factor important in explaining some of the changes in axonal connections after early lesions. Developing axons not only compete with other axons for terminal space, spreading into denervated territories [Raisman, 1969; Schneider, 1973]. They also tend to conserve the total size of their terminal arbors so that if they are blocked from one region, e.g., by a kind of pruning lesion, they can show a compensatory sprouting in other regions. I nick-named this factor the 'pruning effect' [Schneider, 1973] - and this name has persisted ever since, and is better known than the more formal description of a tendency for a neuron to conserve the total quantity of its axon's terminal arbor. Support for this kind of conservation in axonal end arbors was extended to the level of synaptic number, albeit in the superior cervical ganglion, in a study by Raisman's group [Ostberg et al., 1976]. Further evidence for this factor, or principle, was obtained in my own laboratory in work on both the visual system [Sabel and Schneider, 1988] and the olfactory system [Devor and Schneider, 1975].

I did not try to submit the next paper to Science again, although I had done a great amount of additional work which I had begun to present at professional meetings.
Instead I submitted it to Brain, Behavior and Evolution. It presents a series of experiments with results that clearly support two distinct factors underlying the formation of abnormal connections in the damaged developing brain. It was well received by reviewers. It is, I believe, one of my best papers. I was very happy to learn that it is one of the 'citation classics' of Brain, Behavior and Evolution.

I have been pleased with the impact that these studies have had on subsequent work by others. I will cite two areas. The first is the area of comparative neuroanatomy and brain evolution. My findings led me to have many discussions with the comparative neuroanatomist Sven Ebbesson, and my findings had some influence on his development of ideas on brain evolution leading to his well-known 'parcellation hypothesis' [Ebbesson, 1980, 1984]. (At one point Sven asked me to join him as co-author in working on and describing the hypothesis, but I, regretfully, declined.) It is an area that has been a special interest of mine since graduate school, when I had the great pleasure of interacting with Harvey Karten at MIT, when he was working in Nauta's lab. Evolution has long been important in my thinking and teaching, but the only article I have written that was directly focused on that area was a brief discussion of Ebbesson's article in 1984 [Schneider, 1984].

The second area concerns the new hypothesis presented in my second article in Brain, Behavior and Evolution. Evidence has been reported for a similar kind of compensatory sprouting in other systems, with indications of a 'conservation of terminal quantity' [e.g., Bjorklund and Stenevi, 1979]. Such neuronal regulation is probably very important in changes underlying learning [Turrigiano and Nelson, 2000]. Dendrites of some neurons appear to have a similar regulation of branch number [Samsonovich and Ascoli, 2006]. The intrinsic mechanisms may be related to neuronal regulation of excitability [Marder and Goaillard, 2006; Bucher, 2009]. I believe that much work on these and related factors remains to be done, especially at the cell and molecular levels. 


\section{References}

Bjorklund A, Stenevi U (1979): Regeneration of monoaminergic and cholinergic neurons in the mammalian central nervous system. Physiol Rev 59:62-100.

-Bucher D (2009): Neuronal homeostasis: does form follow function or vice versa? Curr Biol 10:R64-R67.

Devor M, Schneider GE (1975): Neuroanatomical plasticity: the principle of conservation of total axonal arborization; in Vital-Durand F, Jeannerod M (eds): Aspects of Neural Plasticity. Lyon, INSERM, vol 43, pp 191-200.

Ebbesson SOE (1980): The parcellation theory and its relation to interspecific variability in brain organization, evolutionary and ontogenetic development, and neuronal plasticity. Cell Tissue Res 213:179-212.

Ebbesson SOE (1984): Evolution and ontogeny of neural circuits. Behav Brain Sci 7:321-331.

-Marder E, Goaillard JM (2006): Variability, compensation and homeostasis in neuron and network function. Nat Rev Neurosci 7:563574 .
Ostberg AJ, Raisman G, Field PM, Iversen LL, Zigmond RE (1976): A quantitative comparison of the formation of synapses in the rat superior cervical sympathetic ganglion by its own and by foreign nerve fibres. Brain Res 107:445-470.

-Raisman G (1969): Neuronal plasticity in the septal nuclei of the adult rat. Brain Res 14 25-48.

Sabel BA, Schneider GE (1988): The principle of 'conservation of total axonal arborizations' massive compensatory sprouting in the hamster subcortical visual system after early tectal lesions. Exp Brain Res 73:505-518.

Samsonovich AV, Ascoli GA (2006): Morphological homeostasis in cortical dendrites. Proc Natl Acad Sci USA 103:1569-1574.

Schneider GE (1967): Contrasting visuomotor functions of tectum and cortex in the golden hamster. Psychol Forsch 31:52-69.
Schneider GE (1969): Two visual systems. Science 163:895-902.

Schneider GE (1970): Mechanisms of functional recovery following lesions of visual cortex or superior colliculus in neonate and adult hamsters. Brain Behav Evol 3:295-323.

Schneider GE (1973): Early lesions of superior colliculus: factors affecting the formation of abnormal retinal projections. Brain Behav Evol 8:73-109.

Schneider GE (1979): Is it really better to have your brain lesion early? A revision of the 'Kennard principle'. Neuropsychologia 17: 557-583.

Schneider GE (1984): Axon development and plasticity: clues from species differences and suggestions for mechanisms of evolutionary change. Behav Brain Sci 7:46-47.

Turrigiano GG, Nelson SB (2000): Hebb and homeostasis in neuronal plasticity. Curr Opin Neurobiol 10:358-364. 